tant with chronic exhausting diseases, such as tuhereulosis, and it is in all probability the same with leprosy. In leprosy sweating often follows the severe chills during the febrile attacks when the patient is certainly in a low physical condition.

Chills. The patient may at irregular intervals suffer from true chills, as has already been mentioned, and at such times as active inflammatory changes take place, and tissues break down, and ulcers occur. It is possible to consider such chills as the result of the softening and breaking down of nodules and other areas of infiltration and that the bacilli, or their toxic properties, are then set free and taken into the blood stream with the resulting disturbance. Chills with septic infection, typhoid and malaria, are of course well known, and the analogy here is not at all far drawn. These chills are often severe, with great systemic disturbance, the patient is prostrated, the temperature may jise three or four degrees or suddenly drop to subnormal, with the pulse essentially agreeing with the temperature. The chills last from a few minutes to the greater part of an hour, and may occur as often as four or five times in twenty-four hours; or again there may be a single ehill, without recurrence for months.

Apart from the occurrence of true chills, chilliness is often a complaint, and more marked with the patients who are anemic. Chilliness may be complained of on the brightest. and sumniest days and when the patient is free from all other symptoms and is not associated with digestive or intestinal troubles. The question of the blood picture during true chills will be dealt with in another note. In the anesthetic cases here, no chills or feeling of chilliness has been noticed, it being most noticeable in the far advanced tubercular leprosy patients.

\section{NOTES AND CONCLUISIONS.}

A. When the disease is advanced the patient's health varies daily; he feels exceptionally well one day and the next presents every symptom and appearance of a seriously sick person.

13. In comparison to the severe symptoms and general appearance of the patient, physical examination will reveal nothing. Lungs and abdomen are normal, and with the exception of a soft systolic murmur over the precordia, the lieart is normal.

C. During eruption the skin is usually hot and dry.

D. Extreme mental depression at irregular intervals and nervousness are characteristic of every case.

it. Uleers may heal rapidly and continually, or', as is seen in one or two eases, they become chronic and refuse to respond to treatment. Medicinal treatment varies in each case; in leprosy this fact is partieulary aecentuated.
F. The clinieal symptoms of leprosy, although somewhat confused and often indefinite, are, nevertheless, correct symptoms of the disease and in the care and treatment of leprosy patients, are to be carefully observed and seriously considered. The consideration of the pulse, temperature and blood are so important and instructive, that a more careful study is being made and will, in all probability be reported in the future.

In conclusion $I$ wish to thank Dr. Frank $H$. Parker, superintendent Penikese Island Hospital, for his kindly advice and criticism in the preparation of this paper.

\section{INS'TI'TU'TIONAL DENTISTRY : METHODS : RESULTS. REPORT NO. 2.}

BY YREDERICK A. KEYEN, D.M.D., BOSTON.

In the issue of the Boston MEdic.s, AND SurGicar Journal of July 25,1912 , there was printed an article entitled "Institution Dentistry: Methods ; Results," in which I submitted to the medical profession a report of dental work done at St. Vincent's (Orphan Asy'm, Boston, and its relation to the infectious diseases of childhood. 'This statistical report, showing the great decrease of infectious diseases at the orphanage after the establishment of a dental infirmary, amazed even the most enthusiastic propagators of oral hygiene.

Owing to the frequent inquiries regarding the progress of the work since the publication of this article and the many urgent requests for further information, I have deemed it expedient to submit the following report of the last 18 months' work.

The number of children at the Asylum January $11912 \ldots .227$

Children received during the year 76

(Yhildren cared for by the Home during the year.......... 303

Children taken out by relatives... 121

Children in Asyhum Jan. 1, 1913. . 182

'The system of dental work remains the same. The inspection of the ehildren monthly to see that they are keeping their mouths elean and the admonition of the few that are negligent in this respeet has been rigidly observed. The tooth brush brigades, led by the older girls, are recomplishing the desired results, i.c. teaching the younger ehildren how and when to brush their teeth, so that the habit thus formed in child. hood may continue throughont life. A nitrous oxide oxygen apparatus has been installed and found to be a most valuable, though expensive, adjunct in the elimination of pain. 
The following statisties contain the record of work done for the past 18 months. For those who have not read the first article, statistics for the first 18 months are included,-with a partial account of the money expended for materials necessary during that period:

Total number of different patients exam

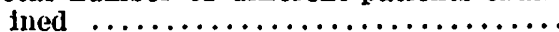

Total number of cleanings $\ldots \ldots \ldots \ldots \ldots, 272$

Total number of cement fillings ....... 25

Total number of amalgam fllings ..... 72

Total number of cement amalgam tillings 69

Total number of temporary fillings ..... 130

Total number of oxphas cu. flllings .....

Total number of teeth extracted (temporary ) $\ldots \ldots \ldots \ldots \ldots \ldots \ldots \ldots \ldots$

Total number of teeth extracted (permanent) $\ldots \ldots \ldots \ldots \ldots \ldots \ldots \ldots \ldots \ldots$

Total number of abscesses opened ......

Total number of gums cut for permanent

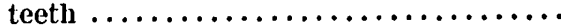

Total number of plastic operations .....

Total number examined and treated .... 1421

Total number of fillings (including temporary).$\ldots \ldots \ldots \ldots \ldots \ldots \ldots \ldots \ldots$

Total number of teeth extracted (includ-

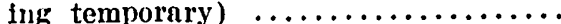

Total time spent (hours) $\ldots \ldots \ldots \ldots \ldots, 210$

\section{Account of Dxpenses.}

Initial cost (chair, engine sterilizers,

brushes, etc.) ............... \$125.00

Supplies for 18 months ..........66.63

Nitrous oxide oxygen apparatus (in-

itial cost) $\ldots \ldots \ldots \ldots \ldots \ldots \ldots \ldots$

Supplies for 18 months, including gas

and oxygen..$\ldots \ldots \ldots \ldots \ldots \ldots$.

Totals ................\$191.63 \$161.15

A study of the above tables will show the great number of teeth filled and the few extractions necessary in the last 18 months in comparison with the preceding 18 months. It is hoped that, after all cavities in the mouths of the permanent inmates of the Asylum are filled, the future work will be solely prophylactic treatment (cleaning). But every year there is an influx and exit of from 75 to 100 new children. Therefore, extraction and filling will necessarily be the first important factor. After filling and extraction are completed, the cleaning of the teeth every three months by the dentist and daily by the patient is expected to prevent future caries in the children's mouths. Contrary to the usual routine, dental repair work is done on the older girls in preference to the younger ones, since the older girls are liable to leave the Asylum first and it is our desire to send them out into the world with mouths free from all carious cavities. Odontalgia has been practically eliminated.

Below is printed a table containing the number of infectious diseases occurring at the Home in the last 36 months, together with statisties of previous years.

\section{RECORD IN REGARI TO INHECTIOUS} UISISASES. 1000 Nov., Apr., May, May, 1010 1011 1012 1018 $\begin{array}{lllll}1907 & 1008 & \text { Nov., Apr., May, May, Nov., } \\ 10081000 & 1010 & 1911 & 1012 & 1013 \\ 6013\end{array}$ $\begin{array}{ccccccc}1008 & 1000 & 1010 & 1911 & 1012 & 1013 & 1013 \\ 6 & 2 & 1 & 0 & 0 & 0 & 1\end{array}$

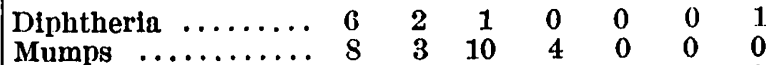

$\begin{array}{lllllllll}\text { Mumps } \ldots \ldots \ldots \ldots & \ldots & \& & 3 & 10 & 4 & 0 & 0 & 0 \\ \text { Scarlet fever } \ldots \ldots \ldots & \ldots & \ldots & 8 & 12 & 8 & 0 & 0 & 0\end{array}$

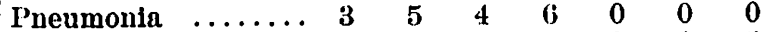

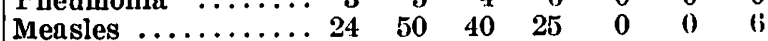

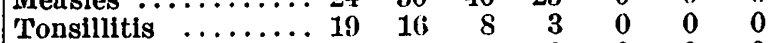

$\begin{array}{llllllll}\text { Whooping cough } \ldots . . . & 7 & 2 & 2 & 0 & 0 & 0 & 0\end{array}$

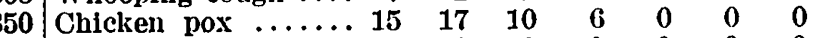

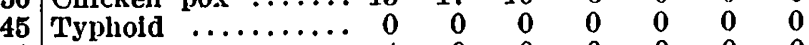

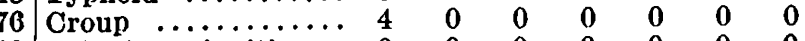

$\begin{array}{lllllllll}\text { Spinal meningitis ... } & 0 & 0 & 0 & 0 & 0 & 0 & 0\end{array}$

$\begin{array}{lllll}\text { Scarlatina } \ldots \ldots \ldots \ldots & 0 & 0 & 0 \\ \text { Bright's (acute) } \ldots . & 0 & 0 & 0\end{array}$

Hemorrhage $\ldots \ldots$....

Tuberculosis of eye.

Tuberculosis of lungs

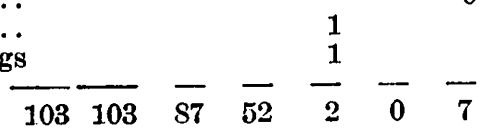

From the above data it may be seen that in 4 the last 36 months only 7 cases of infectious diseases have occurred at the Asylum. Of these 6 were measles, one of which was contracted before or immediately after admittance to the Home. The disease spread to 5 children, permanent inmates of the Asylum. The mouths of all six patients were carefully examined and found to be in need of dental treatment. Whereas in previous years $40-50$ children were stricken down with measles this year only 5 children contracted the disease. The one case of diphtheria also occurred in a new girl. Ex. amination of her mouth showed great need of dental work.

What is the cause of this elimination of disease from St. Vincent's Orphanage immediately after the beginning of dental work and the continuing of this immunity for a period of three years? Dentists need no longer claim to be great prophylactic agents in the field of medicine; for the above statistics demonstrate convincingly the immunity acquired from infectious diseases of childhood after the proper treatment of the child's oral cavity.

For many years dentists have spent much time and effort in compiling and presenting statistics showing the relation existing between carious teeth and infectious diseases of childhood. In many large cities these efforts are bearing fruit. It is, however, hard to understand why there should be so much delay in some parts of this country, especially in Boston, in meeting this problem. At present there exist in other municipalities many methods of handling the public school question, most of which are still in the experimental stage but are nevertheless accomplishing a great deal of good. In Boston, however, the dental question is most unsettled. Spasmodic attempts, most of them theoretical, to remedy this defect in the past have been unsuccessful. At present, even with the new Forsyth Dental Infirmary, the results predicted will be merely scroning the surface. 'The 
Forsyth Dental Infirmary in full working order will be able to handle only a part of the carious cavities now existing in the mouths of the Boston public school children. The good that is to be obtained from this great philanthropy cannot be over-estimated; but without the co-operation of the City of Boston and the medical profession the desired results will fall short.

Establishment of school dental clinies working harmoniously with the Forsyth Dental Infirmary, to my mind, is essential in handling the 100,000 children in the Boston public schools. The 64 chairs at the Forsyth Institute are inadequate to meet the needs of the public school children.

Paid dental inspectors should be appointed by the City after competitive examinations similar to those now in vogue for the school physicians. To permit school nurses to act in the capacity of dental inspectors is indeed a sad commentary upon the importance of this great field of medical science. Nurses are no more competent to judge between dental conditions needing immediate care than they would be in diagnosing adenoid or tonsillar diseases.

Paid dental inspectors are necessary to handle the public school question. Even though the time has not yet come when school dental infirmaries are to be established necessitating dental inspectors in the public schools, even now under the present conditions the Forsyth Institute is in dire need of inspectors in the schools to send them cases needing immediate treatment.

Dentists are very apt in their over enthusiasm upon this subject to momentarily offer their services free to the municipalities. But no work of any great value requiring all a man's working hours was ever well and properly done without monetary compensation.

Progress in school dentistry must come. Further agitation should not be necessary. Physicians should co-operate with dentists and school authorities to demand that steps be taken to eliminate the present conditions existing in the mouths of the public school children.

\section{A FURTHER REPORT ON THE MAYO- GILLIAM OPERATION FOR RETROVER- SION OF THE UTERUS.}

II IIAROLD W. BAKER, M.D., BOBTON,

Surgeon to Out-Patients, Free Hosiptal for Women, Brookline, Mass.

$\Lambda \mathrm{s}$ pointed out in a previous paper, ${ }^{1}$ the best method for the treatment of retroversion of the uterus, is the operative treatment, wherein the Mayo modification of the Gilliam technique is used. The steps of this operation have been gone over in the previous paper, and we do not need to refer to them again.
The three elasses of operations performed by the best authorities for retroversion, may well be described here with their results. They are :-

1. Hysterorrhaphy, which may be divided into two classes, namely

a. Suspension.

b. Fixation.

2. Intraperitoneal shortening of the round ligaments.

3. Extraperitoneal shortening of the round ligaments.

By suspension, we mean the mere suturing of the uterus to the peritoneum. This method has proved by long and extensive use to have too many recurrences to justify the continuance of this attempt to cure. This fact was shown in the first paper'.

By fixation, we mean the suturing of the uterus to the abdominal fascia. This procedure, on the other hand, has demonstrated that it actually does accomplish the purpose for which it is done. The objection to fixation is not failure to do what it purports to do, but that complications from it $^{6}$ are too serious and numerous to warrant doing it during the childbearing period. There is a fault common to both suspension and fixation, in that they are not anatomically justified, for the uterus is normally a movable organ, and they both attempt to immobilize the uterus.

We believe that the intraperitoneal shortening of the round ligaments, as done by Baldy, Webster, $^{7}$ Coffey $^{3}$, and others, is giving much better results than it did five to ten years ago, when we saw a recurrence in thirty-one out of thirtyfive cases ${ }^{1}$. We object to this procedure, however, as it utilizes the weakest part of the ligaments to do the heaviest part of the work. 'The chance for recurrence is still very great.

The extraperitoneal shortening of the round ligaments, the Alexander type of shortening ${ }^{2}$, is good, but it has a moderately high percentage of failure. The reason for this percentage ${ }^{1}$, is due in all probability to the fact that adhesions of the uterus are not easily recognized even when the patient is fully anaesthetized. The operation utilizes the strongest part of the ligaments, and it does not interfere with the normal motility of the organ. There is one distinct disadvantage to this operation, and that is that the surgeon is unable to examine the other $a b-$ dominal organs.

We have begun to emigrate from the old idea that the best surgeon is the one who makes the smallest incision, and who does the least exploring. The patient is apt to embarrass her surgeon, a year or two later, if she comes back to him (or to another), with other abdominal trouble which might have been found and relieved by abdominal exploration at the time of the former operation. We prefer to know that the abdomen is completely negative, rather than to go on any assumption. The knowing adds nothing to the risk of the operation, and it adds much to the mental comfort of the patient, and 